\title{
Design of Pedestrian Landscape Flying-Bird Arch Bridge with Cable-Stayed Cable and Lissajous Curved Arch Rib
}

\author{
Guangchuan $\mathrm{Zhu}^{1 *}$, Wenping $\mathrm{Xu}^{1}$ and Jinfa $\mathrm{Xu}^{2}$ \\ ${ }^{1}$ College of Civil Engineering, Southeast University Nanjing, China,210096 \\ ${ }^{2}$ Jiangsu traffic engineering consulting and Supervision Co., Ltd, Nanjing, China, 211800
}

\begin{abstract}
In view of the demand of super long span pedestrian landscape bridge with curved deck, this paper proposes a kind of cable-stayed and flying-brid arch bridge with Lissajous curved arch rib and double curved bridge deck. Its plane positive projection is Lissajous curve figure, the side elevation of the arch rib is the shape of the cable-stayed and flying-brid arch, and the arch foot cable and the upper space cable between the arch ribs are installed on the Lissajous spatial curved arch rib with concrete-filled steel tube to form a self balanced structure system, which floats and drags across the river. The main arch sling and the tail cable are installed, the double curved bridge deck and the central circular sightseeing platform are suspended, and multiple groups of spatial cables work well together to complement each other, with having complementary advantages. Combined with the actual project, the parameter design is carried out, the Midas finite element model is established, the internal force of the structure is calculated, the structural dynamic mode and stability analysis are carried out, the rationality of its structural performance is verified by analysis and research.
\end{abstract}

\section{Introduction}

With the development of the times, the spans of pedestrian landscape bridges are getting larger and larger. At the same time, more and more landscape bridges require the use of beautiful curved bridge decks. How to balance the mechanical performance requirements of super large-span structures and the aesthetic requirements of curved bridges is faced by bridge engineers ${ }^{[1-4]}$.

When the curved bridge of the landscape river park has a large span, the beam bridge will encounter considerable difficulties in structure and construction ${ }^{[5-7]}$, if a largespan concrete-filled steel tube flying swallow arch rib is used to suspend the double-span curve bridge deck, it is very suitable. A bridge across the river has a special and beautiful shape in aesthetics.

The cable-stayed flying swallow arch is a combination of a cable-stayed structure and a flying swallow arch bridge. The flying swallow arch bridge is the mainstay, and the cable-stayed structure is auxiliary. It is the product of the brave exploration of bridge design and construction technology. The cable-stayed flying-swallow arch has a novel structure and beautiful appearance, showing the characteristics of the flying swallow arch bridge and the cable-stayed bridge ${ }^{[8-10]}$, the two bridge types work together and have complementary advantages.

In this paper, combined with a pedestrian landscape bridge in an ecological river, the geometric configuration research of the flying-swallow type cable-stayed arch bridge based on Lissajous's curved arch ribs is carried out, engineering parameter design is carried out, and the Midas finite element model is established for internal force analysis, modal analysis and stability analysis research to verify the rationality of its structure.

\section{Geometric configuration study}

The width of an ecological landscape river is 150 meters. Taking into account the requirements of the landscape, it is necessary to construct a double-span curve-shaped pedestrian landscape steel tube concrete flying swallow arch bridge, hoping to enhance the cultural landscape effect of the river park.

According to the smooth and graceful Lissajous curve graphics, the steel pipe is bent into Lissajous curve-shaped swift-stayed arch ribs by the pyrotechnic simmering process, and the lower tie rods between the arch ribs and the upper space cables between the arch ribs are set, to form a self-balanced structural system, reduce the unbalanced internal force of the support, and improve the bearing performance of the Lissajous figure steel tube concrete space arch rib. The space arch rib is equipped with slings and cable-stayed cables to suspend the doublewidth curved bridge deck, forming a flying-swallow type cable-stayed arch bridge with a double curved deck with Lissajous figure.

The Lissajous figure is a figure formed by using an oscilloscope to input different sinusoidal signals on the $\mathrm{X}$ axis and Y-axis and superimposing them. The Lissajous figure is a regular and stable closed curve composed of simple harmonic vibrations of simple integer ratios, formed by two frequencies in mutually perpendicular directions. 
The parameter equation of Lissajous figure is:

$$
\mathrm{x}(\theta)=\operatorname{asin}(\theta)
$$$$
\mathrm{y}(\theta)=\mathrm{b} \sin (\mathrm{n} \theta+\varphi)
$$

in which $\mathrm{n} \geq 1$ and $0 \leq \varphi \leq \frac{\pi}{2}$.

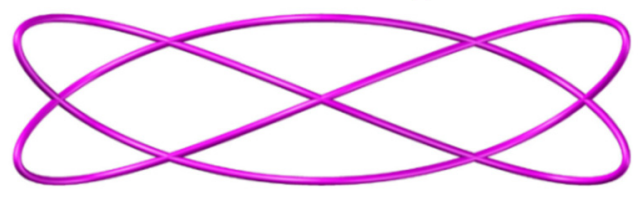

Fig1. The Lissajous figure

According to the structural characteristics of the flying -swallow type cable-stayed arch bridge, the spatial cable structure system of this bridge is composed of four parts: the lower tie bar between the arch ribs, the upper space cable between the arch ribs, the main arch sling and the rear stay cable. The spatial cables work together and complement each others' advantages, greatly improving the mechanical performance of the Lissajous-shaped concrete-filled steel tube flying swallow arch bridge structure.

The bridge adopts the construction technology of floating and dragging across the river. The lower tie rods between the arch ribs and the upper space cables between the arch ribs are installed, and the lower temporary cross cables between the arch ribs and the lower temporary transverse cables are installed to form a self-balanced structural system. Drag the Lissajous curve-shaped swallow arch across the river and place it on the foundation of the arch bridge smoothly. After the bridge is completed, the lower temporary cross cable and the lower temporary horizontal cable are removed.

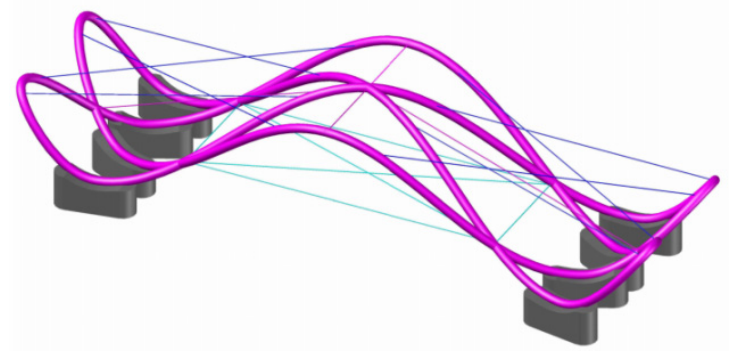

Fig2. Inter-arch space cable

In terms of structural mechanics, the flying-swallow type cable-stayed arch bridge structure is like a giant cantilever beam structure, which can be divided into two stress areas: the cantilever part and the mid-span part. The cantilever part needs to be equipped with upper cables, and the mid-span part needs to be configured with lower cables.

Among them, the lower tie rod cable between the arch ribs is composed of two permanent cables on the left and right, a temporary cross cable, and a temporary transverse cable. The lower tie rod cable of this bridge is mid-through, and the lower tie rod cable between the arch ribs is anchored at the X-shaped cross node of the Lissajousshaped flying swallow arch, which is convenient for construction, convenient anchoring, and reasonable stress. The lower space between the arch ribs is like a wire cable with a positive bending moment, which can improve the flying swallow's bearing capacity and structural rigidity of the mid-span part of the arch structure.

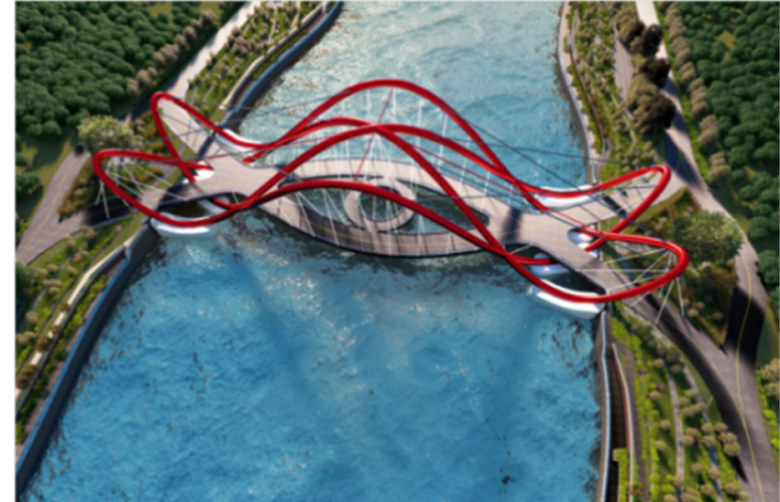

Fig3. Effect picture of flying-swallow style cable-stayed arch bridge with Lissajous curve arch rib

Install the main arch sling in the middle section of the Lissajous curve-shaped flying swallow arch rib, and install the oblique sling in the tail section of the arch rib. Lissajous's curve-shaped flying swallow-style cablestayed arch rib structure suspends the double-width curveshaped bridge deck, and the construction of the bridge deck stiffening beam is convenient.

The double-width curved bridge deck is composed of double-width cross-curved main beams and circular ring beams. The circular ring beam is located at the center of the double-width cross-curved main beam, which limits the relative displacement and deformation of the left and right double-width cross-curved main beams, can greatly improve the lateral structural force of the double-width cross-curved main beam, and can double as a sightseeing platform.

The flying-swallow type cable-stayed arch bridge with a double-span curve deck has the characteristics of a flying swallow-style cable-stayed arch bridge in the longitudinal direction, and its transverse direction is like a cable-stayed bridge system with inclined arch towers. Lissajous curve space inclined arch rib design is ingenious, with beautiful shape, rich facade, convenient construction of replacing cables, large spanning ability and good durability.

The cable-stayed flying swallow arch pedestrian landscape bridge with curved arch ribs of Lissajous has a beautiful shape like a three-dimensional sculpture, like a dancing butterfly. A variety of curved design elements are integrated into the design, which is a perfect combination of geometry, architecture and structure, becoming a threedimensional space curve pedestrian landscape bridge.

\section{Design parameters}

An ecological river has a landscape belt with parallel rivers built on both banks. The width of the river is 150 meters. The Lissajous curve-shaped flying swallow-style cable-stayed arch bridge with double-curved bridge decks spans the landscape river. The total length of the main span bridge is 190 meters, and the span is $40 \mathrm{~m}+110 \mathrm{~m}+40 \mathrm{~m}$. The seismic fortification of this bridge is 6 degrees. 

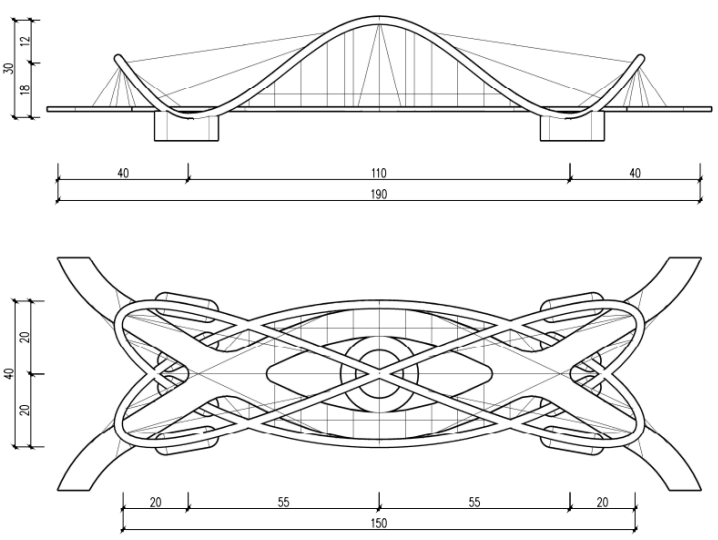

Fig4. General layout

Lissajous curve-shaped flying swallow arch rib is composed of three components connected end-to-end butterfly wing inclined arch rib, X-shaped cross-shaped arch rib and flying swallow inclined tower arch rib. The three steel pipe members are welded and connected as a whole. The plane orthographic projection is a three-leaf rose line figure, and the side elevation projection of the arch rib is a flying-swallow type cable-stayed arch bridge structure.

The horizontal projection length of the Lissajous graphic steel tube arch rib is 150 meters, the horizontal projection width is 40 meters, and the distance between the supports of the spatial arch rib is 110 meters. The diameter of the circular steel pipe of the arch rib is 2 meters, the wall thickness of the steel pipe is $20 \mathrm{~mm}$, and the inside of the steel pipe is filled with C50 concrete.

Lissajous curved flying-swallow arch ribs are installed with lower cables between the arch ribs and cables for the upper spaces between the arch ribs to form a self-balanced structural system. The floating plan is used to drag across the river, lift and translate, and place the flying swallowstyle cable-stayed arch ribs on the foundation of the arch bridge smoothly.

The lower tie rod cable between the arch ribs is anchored at the $\mathrm{X}$-shaped cross node of the Lissajous figure flying-swallow arch, forming a mid-through flying swallow arch bridge structure. There are 6 sets of archfoot cables, of which the left and right permanent cables use $1770 \mathrm{MPa}$ galvanized high-strength steel wire, and each permanent arch-foot cable has a diameter of 0.4 meters. Besides, two high-strength steel wires of temporary cross cables with a diameter of 0.2 meters and a high-strength steel wire of temporary cross cables with a diameter of 0.1 meters are set up. After being dragged across the river by floating, 4 sets of temporary cables are removed.

The cable system of the upper space between the arch ribs is composed of three parts: the upper stay cable between the arch ribs, the longitudinal cable and the horizontal cable. The upper space cables between the arch ribs are made of $1770 \mathrm{MPa}$ galvanized high-strength steel wire, and the arch rib space cable system is like a negative bending moment wire cable, which can improve the bearing capacity and structural rigidity of the flyingswallow type cable-stayed arch structure.

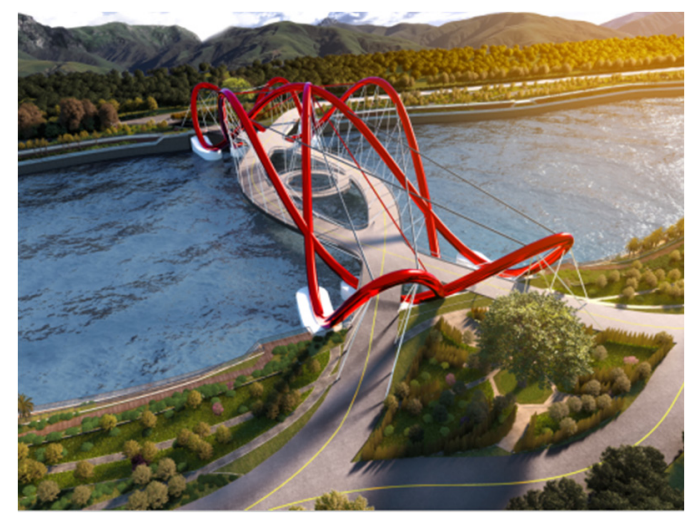

Fig5. Effective picture of the completed bridge

The horizontal stay cables are anchored on the tops of the two left and right wing-shaped inclined arch ribs. The horizontal stay cable adopts high-strength steel wire cables with a diameter of 0.2 meters. The horizontal stay cables can ensure the overturning stability of the wingshaped inclined arch ribs;

Longitudinal cable anchoring starts at the intersection of two swallow-like inclined tower arch ribs at one end of the arch bridge, spans the apex of the X-shaped crossshaped arch rib, and anchors at the intersection of two swallow-like inclined tower arch ribs at the other end of the arch bridge. The longitudinal cable adopts a highstrength steel wire cable with a diameter of 0.2 meters;

The upper cable between the arch ribs are set between the butterfly wing-shaped inclined arch rib and the flying swallow-shaped inclined tower arch rib. The stay cable adopts a high-strength steel wire cable with a diameter of 0.15 meters. There are four cables on each side, and there is a total of eight cables between the arch ribs.

The double-width cross-curved main beam is a flat steel box beam structure with a beam height of 1.3 meters and a beam width of 9 meters. The circular ring beam is a steel box beam structure with a beam height of 1.2 meters and a beam width of 4 meters.

The sling system consists of three parts: the main arch herringbone sling, the circular central sling and the tail stay cable. The sling system suspends the double-width curved bridge deck and the central circular ring beam, the upper part of the herringbone sling is anchored on the butterfly wing-shaped inclined arch rib, and the lower part of the herringbone sling suspends the middle beam section of the double-width cross-curved main beam. The herringbone sling adopts a $1770 \mathrm{MPa}$ high-strength steel wire cable with a diameter of 0.10 meters, the spacing of the herringbone slings is 7.5 meters, each of 9 pairs of herringbone cables, and a total of 18 pairs of herringbone cables for the whole bridge.

The upper part of the tail stay cable is anchored on the arch rib of the flying-swallow type inclined tower, and the lower part of the tail stay cable is inclined to lift the two side span sections of the double-width cross-curved main beam. The rear stay cable adopts $1670 \mathrm{MPa}$ high-strength steel wire cable with a diameter of 0.10 meters, and there is a total of 24 rear stay cables for the whole bridge.

The upper part of the central sling of the ring is anchored on the top of the X-shaped cross-shaped arch rib, and the lower part of the central sling of the ring is suspended from the circular ring beam. The circular ring 
beam has 6 central slings in the inner ring and 4 central slings in the outer ring. The central sling adopts a $1770 \mathrm{MPa}$ high-strength steel wire cable with a diameter of 0.05 meters.

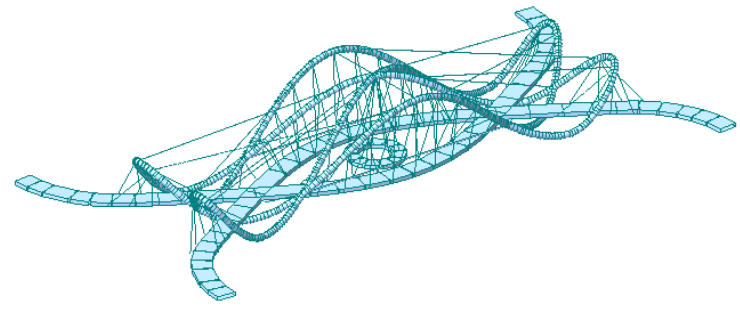

Fig6. Midas model

\section{Calculation results under vertical load}

Considering bridge deck paving and municipal pipelines, the standard value of uniformly distributed load is $6 \mathrm{KN} / \mathrm{m}^{2}$ for the additional dead load on bridge deck, and the standard value of uniformly distributed load is $5 \mathrm{KN} / \mathrm{m}^{2}$ for bridge deck live load. The calculation results under the vertical load are as follows:

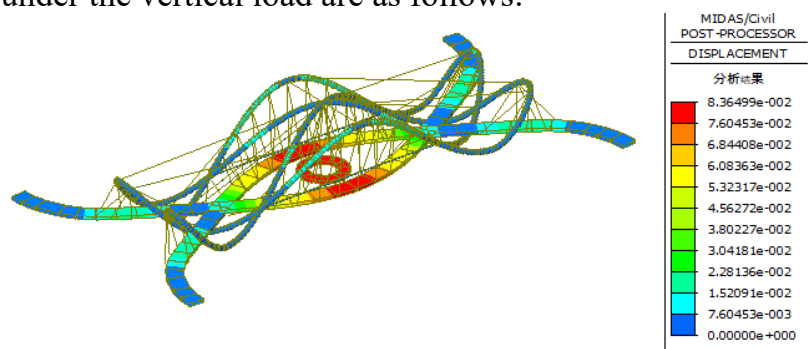

Fig7. Displacement under vertical load (constant and live)

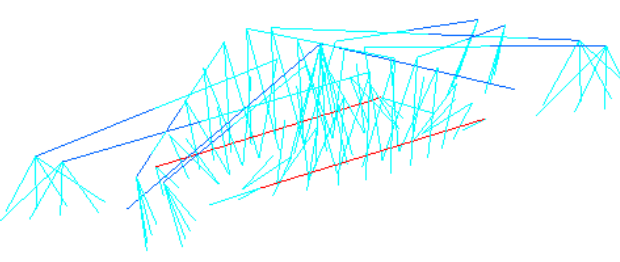

(a) Cable unit internal force

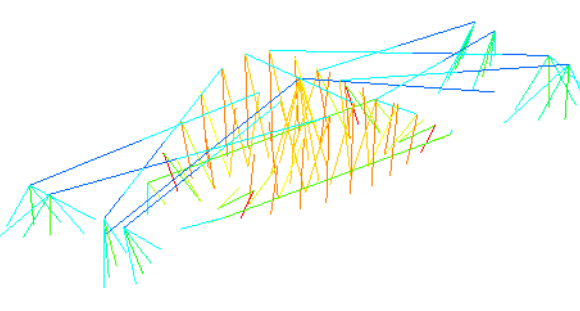

(b) Cable unit internal force
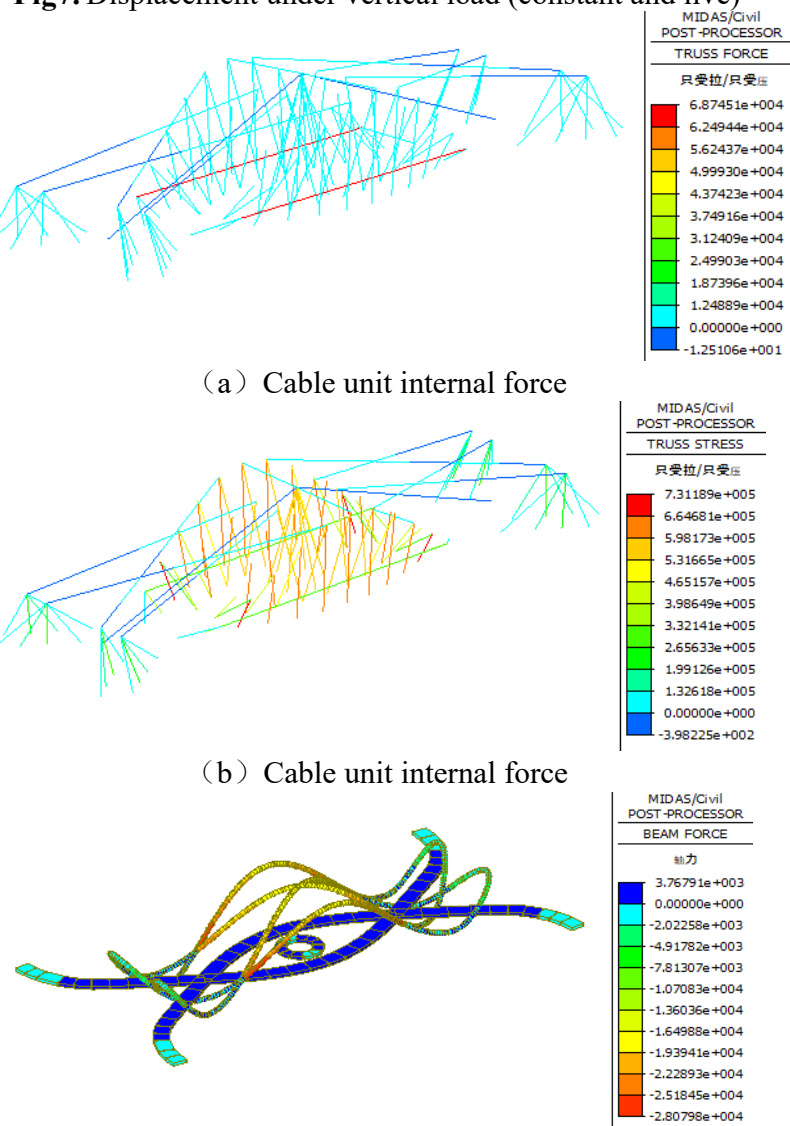

(c) Beam unit internal force

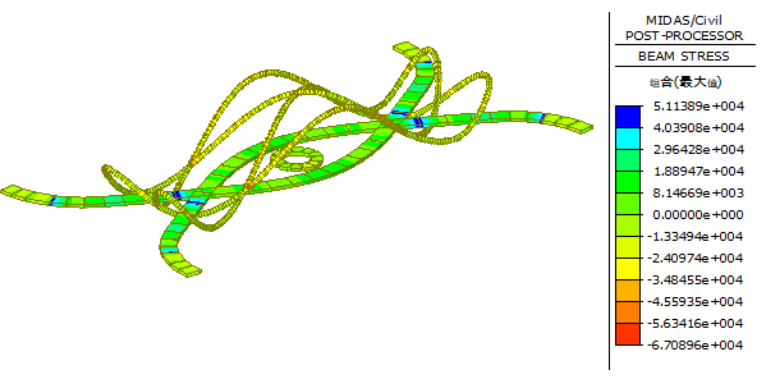

(d) Beam unit internal force

Fig8. Calculation results of internal force and stress under load Under the action of the vertical live load, the maximum vertical displacement appears at the mid-span position, and the maximum deflection is only $0.084 \mathrm{~m}$, which meets the $1 / 500$ limit specified in the code. The vertical structure of the bridge has a relatively large rigidity.

The maximum internal force of the main bridge sling is $8269.6 \mathrm{KN}$, and the maximum stress of the sling is 731.2MPa, which meets the strength requirements.

The maximum internal force of the cable tie is $68745.1 \mathrm{KN}$, and the maximum stress of the tie is $350.1 \mathrm{MPa}$, which meets the strength requirements.

The maximum internal force of the bridge arch is $28079.8 \mathrm{KN}$, and the maximum stress of the bridge arch is $67.1 \mathrm{MPa}$, which meets the strength requirements. The maximum stress of the arch rib appears near the arch foot. The component material is steel tube concrete, the concrete is C50 concrete, and the steel is Q355 steel, which can meet the strength requirements.

\section{Modal analysis results}

In order not to miss any mode shapes, the sub-block method is used to solve the characteristic equations in the analysis process. In the analysis process, the sub-blocking method is used to solve the characteristic equations, the first 20 natural frequencies and the mode characteristics.

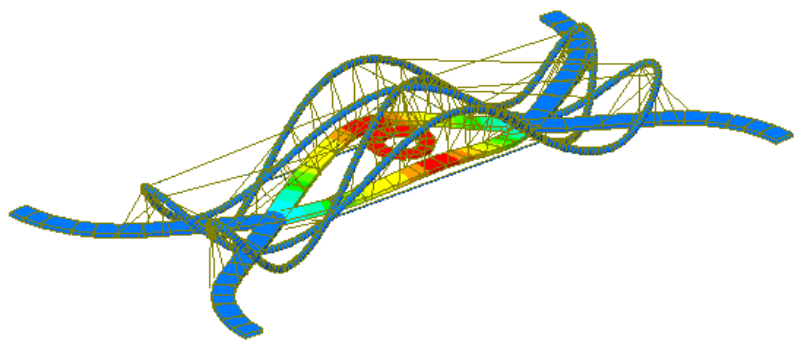

(a) 1st order mode (positive symmetrical vertical bending) $(2.049 \mathrm{~Hz})$

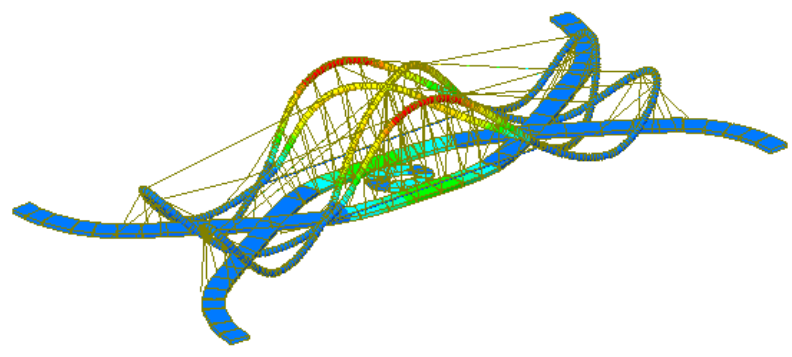

(b) 3rd order mode (positive symmetry side bending) $(2.371 \mathrm{~Hz})$ 


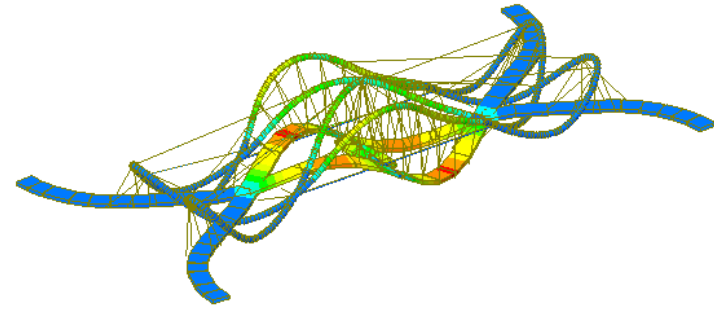

(c) 4th order mode (anti-symmetric vertical bending) $(2.382 \mathrm{~Hz})$

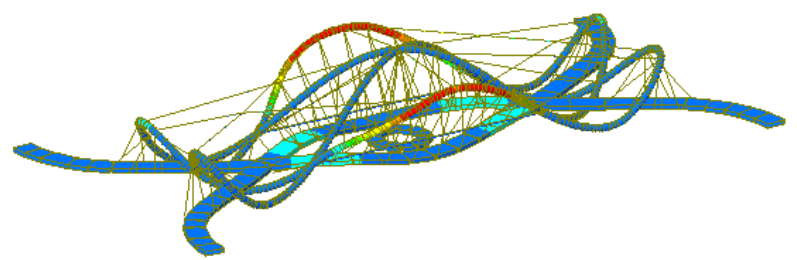

(d) 7th-order vibration mode (the arch is symmetrically bent) $(3.209 \mathrm{~Hz})$

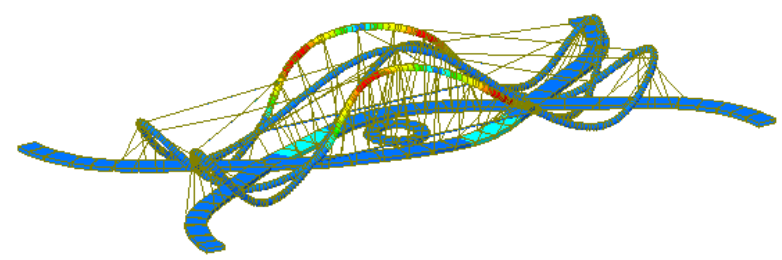

(e) 9 th order mode (anti-symmetric side bending) $(3.453 \mathrm{~Hz})$

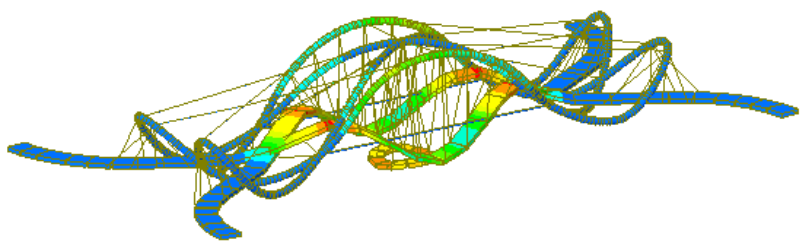

(f) 10th order mode (torsion of bridge deck) $(3.987 \mathrm{~Hz})$

Fig9. Typical modal

From the calculation results in the above figure, it can be seen that the first-order mode is a positive symmetric vertical bending with a frequency of $2.049 \mathrm{~Hz}$; The thirdorder mode is positive symmetrical side bend, and the frequency is $2.371 \mathrm{~Hz}$; The 10th order mode is a torsional mode with a frequency of $3.987 \mathrm{~Hz}$.

On the whole, the vibration modes are dense and there is obvious grouping of vibration modes. The first 9 modes are dominated by lateral and vertical bending vibrations, and the torsional mode does not appear until the 10th order. The higher frequency of each order of the bridge structure indicates that the bridge structure has greater structural spatial rigidity.

\section{Structural stability analysis}

The buckling analysis of the designed bridge was carried out with Midas software, and the structural stability coefficient was obtained. In general, when the stability coefficient is the smallest, the possibility of structural instability is greatest. The following table lists the first 10 order stability factors.
Table1. Buckling mode calculation results

\begin{tabular}{ccc}
\hline Mode & Eigenvalues & Allowable error \\
\hline 1 & 33.391 & $0.0000 \mathrm{e}+000$ \\
2 & 34.244 & $0.0000 \mathrm{e}+000$ \\
3 & 34.537 & $0.0000 \mathrm{e}+000$ \\
4 & 55.016 & $4.2530 \mathrm{e}-029$ \\
5 & 57.132 & $1.0357 \mathrm{e}-026$ \\
6 & 62.403 & $2.0364 \mathrm{e}-018$ \\
7 & 62.642 & $2.9969 \mathrm{e}-018$ \\
9 & 64.602 & $5.4086 \mathrm{e}-017$ \\
10 & 70.887 & $1.1194 \mathrm{e}-011$ \\
\hline
\end{tabular}

It can be seen from the above table that the minimum value of the stability safety factor of the bridge is 33.391 , which fully meets the requirements of GB 50923-2013 "Technical Specification for Concrete Filled Steel Tubular Arch Bridges" greater than 4.0.

The analysis shows that the Lissajous curve-shaped flying-swallow type cable-stayed arch bridge connected end to end has good beam integrity, and the X-shaped cross-shaped arch rib can greatly improve the structural stability.

\section{Conclusion}

Based on the engineering background of a pedestrian landscape bridge with a main span of 110 meters, this paper conducts a research on the geometric configuration of a Lissajous curved flying swallow arch bridge with a double-span curve deck, establishes a Midas finite element model, and conducts the internal force analysis, dynamic mode and structural stability analysis under vertical load have drawn the following conclusions:

(1) According to the smooth and beautiful Lissajous figure, the steel pipe is bent into Lissajous curve-shaped flying swallow arch ribs by the pyrotechnic simmering process. The double-span curve bridge deck and the circular sightseeing platform are suspended to form a Lissajous curve arch rib flying-swallow type cable-stayed arch bridge. The shape is beautiful, like a dancing butterfly, with the beauty of three-dimensional sculpture.

(2) The curved steel tube arch ribs of the super-largespan Lissajous curved arch ribs and flying-swallow type cable-stayed arch bridges are raised and extended to form inclined arched towers, which is made in one go, smooth and continuous, the arch tower is integrated, and the structural integrity and stability are better.

(3) Lissajous curved swift-stayed arch ribs are installed with lower cables between the arch ribs and the upper space cables between the arch ribs to form a selfbalancing structure system, which is dragged across the river by floating, and construction is quick and convenient.

(4) The space cable structure system is formed by the tie rod cable, the space cable between the arch ribs, the main arch sling and the tail stay cable. Multiple groups of space cables work together to complement each other, which greatly improves the mechanical performance of the Lissajous curve-shaped steel tube concrete flying swallow arch bridge structure.

(5) The Lissajous curve-shaped flying-swallow style cable-stayed arch bridge is like a giant cantilever beam structure, which can be divided into two stress areas: the 
cantilever part and the mid-span part. The lower cable between the arch ribs bears a positive bending moment, and the upper space cable between the arch ribs bears a negative bending moment. The bridge has greater structural rigidity and bearing capacity. Under the action of vertical live load, the maximum deflection in the middle of the span is $0.084 \mathrm{~m}$, which meets the $1 / 500$ limit specified in the code.

(6) Modal analysis shows that the frequency of each order of the bridge structure is relatively high, and there is an obvious mode grouping phenomenon, which indicates that the bridge structure has greater structural spatial rigidity. Among them, the first-order mode is positive symmetrical vertical bending, with a frequency of 2.049 $\mathrm{Hz}$, which does not meet the $3 \mathrm{~Hz}$ specification. A mass frequency modulation damper can be added to control its dynamic response to solve the problem of pedestrian comfort.

(7) The Lissajous curve-shaped flying swallow-style cable-stayed arch bridge connected end to end has good structural integrity. Its X-shaped cross-shaped arch rib geometric configuration can greatly improve the structural stability, and the minimum stability safety factor is 33.391 , which meets the requirements of the specification.

\section{References}

1. Kuo, M., \& Xiao-Lan Meng. Towards a landscapeapproach bridge design: Philosophy and practice[C]. 2011 International Conference on Electric Technology and Civil Engineering (ICETCE), 2011.7102-7106.

2. B. Briseghella, L. Fenu, W. Huang, et al.Tensegrity footbridges with arch deck: static and dynamic behaviour[C].6th International Conference on Arch Bridges, Fuzhou, 2010.

3. Luigi Fenu, Eleonor Congiua ,Davide Lavorato et al. Curved footbridges supported by a shell obtained through thrust network analysis[J]. Journal of Traffic and Transportation Engineering.2019,6(1):65-75.

4. Wang Tingzheng.Technical characteristics of cablestayed flying swallow arch combination bridge[J]. World Bridges,2009(02):27-30. (In Chinese)

5. Zhao Yueyu, Yang Xiangzhan,Kang Houjun.Analysis of Dynamic Characteristics of Cable-stayed Arch Bridge[J]. Highway,2005,(11).36-39. (In Chinese)

6. Luo Shidong, Wang Xinguo, Wang Tingzheng, et al. Conception and Research on Innovative Technology of Long-span Cable-Stayed Arch Bridge[J]. Bridge Construction,2005,(6).31-33,51. (In Chinese)

7. shi-dong luo, Wang Xinguo ting-zheng wang, cassia Xing. Innovative Design and Research of long-span cable-stayed Arch Bridge [J]. Bridge Construction,2005(06):31-33+51.(In Chinese)

8. Lv Jiangen, Wang Ronghui. Comparison of mechanical properties between cable-stayed arch Composite bridge and ordinary arch Bridge [J]. Highway,2008(08):5-9.(In Chinese)

9. Wang Tingzheng. Technical Characteristics of Cable- stayed Flying-Arch Composite Bridge [J]. World Bridge,2009(02):27-30.(In Chinese)

10. Chen DE. Structural analysis of cable-stayed arch composite bridge [J]. Journal of natural science of xiangtan university,2009,31(03):123-127.(In Chinese) 